\title{
Derramamento de Óleo no Mar e Implicações Tóxicas da Exposição aos Compostos Químicos do Petróleo
}

\author{
Débora Caribé Passos Silva, ${ }^{1}$ Caroline dos Santos Melo, ${ }^{1}$ \\ Amanda Batista de Oliveira, ${ }^{1}$ Neuza Maria Miranda dos Santos, ${ }^{1}$ \\ Laise Cedraz Pinto ${ }^{2}$
}

\section{RESUMO}

Introdução: O petróleo é um combustível fóssil composto principalmente por hidrocarbonetos policíclicos aromáticos, considerados poluentes orgânicos, bioacumuláveis e que se acumulam ao longo de cadeias alimentares. Recentemente, o derramamento de petróleo, ocorrido no litoral do Nordeste brasileiro, tornou-se um desastre ambiental de grande proporção, com graves impactos ao ambiente marinho e terrestre. Objetivo: Revisar os casos de derramamento de petróleo e suas implicações toxicológicas ao meio ambiente e saúde humana. Método: Foi realizado um levantamento em bases de dados, sendo selecionados estudos nacionais e internacionais para compor esta revisão. Resultados/Discussão: A ocorrência de desastres ambientais de derramamento de óleo no mar e exposição aos constituintes químicos do petróleo promoveram diversos danos ambientais, a exemplo de bloqueio dos sistemas de animais filtradores, prejuízo da ação fotossintética de espécies de plantas, emissão de gases poluentes no ar e diminuição da defesa natural do solo. Na saúde humana são relatados efeitos de carcinogenicidade, hemototoxicidade, neurotoxidade e danos psicossociais. A via mais comum de exposição da população pelo petróleo é a respiratória, podendo ocorrer, também, por ingestão de alimentos e água, considerando que os riscos pela via dietética ainda são pouco esclarecidos. Alternativas têm sido desenvolvidas nos espaços de centros de estudos das regiões afetadas com relação à utilização da grande quantidade de petróleo retirada das praias, inclusive do nordeste brasileiro. Conclusão: São necessários estudos para mensurar o impacto ambiental e na saúde humana a longo prazo, além de estratégias para acelerar a biodegradação desse material contaminante.

Palavras-chave: Petróleo; ambiente marinho; oceano; toxicidade; contaminação

\section{OIL SPILL IN THE SEA AND TOXIC IMPLICATIONS OF EXPOSURE TO PETROLEUM CHEMICAL}

\section{ABSTRACT}

Introduction: Petroleum is a fossil fuel composed mainly of polycyclic aromatic hydrocarbons considered to be organic pollutants, bioaccumulative and that accumulate along food chains. Recently, the oil spill that occurred on the coast of northeastern Brazil has become a major environmental disaster, causing an impact on the marine and terrestrial environment. Objective: To review the cases of oil spills and their toxicological implications for the environment and human health. Methods: A survey was carried out in databases and national and international studies were selected to compose this review. Results/Discussion: The occurence of environmental disasters resulting from the spill of oil in the sea with exposure to the chemical constituents of petroleum promoted environmental damage, for example, blocking the systems of filtering animals, impairing the photosynthetic action of plant species, emission of polluting gases in the air and decreased natural defense soil). In the human health, effects of carcinogenicity, hematotoxicity, neurotoxicity and psychosocial damage have been reported. The most common way of exposure of the population by oil is the respiratory, which can also occur through ingestion of food and water, and the risks through the dietary way are still unclear. Alternatives have been developes, in the areas of study centers in the affected regions, in relation to the use of the large amount of oil taken from the beaches of Northeast Brazil. Conclusion: Studies are needed to measure the long-term environmental and human health impact and strategies to accelerate the biodegradation of this contaminating material.

Keywords: Petroleum; marine environment; ocean; toxicity; contamination

RECEBIDO EM: 9/9/2020

MODIFICAÇÕES SOLICITADAS EM: 9/3/2021

ACEITO EM: 1\%/10/2021

\footnotetext{
${ }^{1}$ Universidade Federal da Bahia. Salvador/BA, Brasil.

2 Autora correpondente. Universidade Federal da Bahia, Escola de Nutrição. Rua Basilio da Gama, s/n - Campus Canela. Salvador/BA, Brasil. CEP 40110-907. http://lattes.cnpq.br/1424276634860744. https://orcid.org/0000-0001-7470-7074. Icedraz@hotmail.com
} 


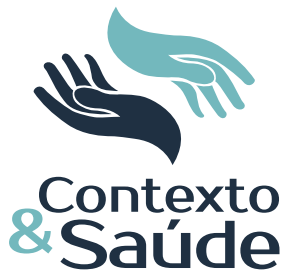

\section{INTRODUÇÃO}

O petróleo é um combustível fóssil que possui diversas aplicações na indústria, como na produção de plásticos, cosméticos e calçados, sendo um dos destaques da economia do Brasil ${ }^{1}$. Para que seja formado é necessário o acúmulo de material orgânico em condições específicas de pressão, isolado em camadas do subsolo de bacias sedimentares².

O contexto no qual ocorreu a ampliação na exploração do petróleo no Brasil se deu em meados do século 20, em decorrência do desenvolvimento do conhecimento geológico e aumento da demanda por derivados do petróleo, como os combustíveis, pois, até então, eram utilizados os provenientes de óleos de origem animal, como o óleo de baleia. Com o aumento da exploração nessa área e a criação da Petrobras, instituída pela Lei no 2.004, de 3 de outubro de 1953, além do crescimento econômico brasileiro, o país consolidou-se como um grande produtor e consumidor desse recurso energético ${ }^{3}$.

Apesar do retorno econômico positivo promovido pela indústria do petróleo, deve-se ter atenção quanto aos recursos naturais consumidos para a sua produção, como a água e o solo, além da formação de resíduos, sejam eles líquidos, sólidos e/ou aéreos ${ }^{4}$ que impactam o ecossistema e, consequentemente, a saúde humana 5 .

Devido à sua estrutura química, o petróleo é uma matéria-prima complexa, cuja composição pode chegar a mais de 40 mil substâncias $^{4}$. Segundo a Agência Nacional do Petróleo, Gás natural e Biocombustíveis ${ }^{6}$, a composição química do petróleo é uma combinação complexa de hidrocarbonetos ( $82 \%$ de carbono e $12 \%$ de hidrogênio) e uma pequena quantidade de nitrogênio (4\%), oxigênio (1\%), compostos de enxofre $(0,5 \%)$ e íons metálicos (0,5\%).

Dentre as substâncias encontradas no petróleo destacam-se os Hidrocarbonetos Policíclicos Aromáticos (HPAs) que, apesar de estarem dispostos em pequenas quantidades, na maioria das vezes são os de maior toxicidade. Segundo o Instituto Nacional do Câncer ${ }^{7}$, os HPAs são poluentes que merecem grande preocupação, uma vez que podem ser encontrados na água, no solo, no ar e em alimentos, posto que as vias de exposição ocorrem, principalmente, por meio da derme, mas também por inalação ativa ou passiva e ingestão. Além disso, são difíceis de serem degradados e podem acarretar em consequências nocivas, especialmente por exposição ocupacional ou desastres ambientais ${ }^{8}$.

A exposição ocupacional a esses compostos pode levar a diversos tipos de câncer, como de o pulmão, bexiga, pele, esôfago e sistema hematopoiético. 0 benzeno, um dos hidrocarbonetos constituintes do petróleo, é considerado um composto cancerígeno e pode causar intoxicação por diversas vias, como inalatória ou dérmica, especialmente em decorrência da exposição ocupacional ${ }^{9}$.

Os efeitos decorrentes à exposição a esses compostos oriundos de desastres ambientais incluem carcinogenicidade, genotoxicidade, lesões pulmonares em decorrência da inalação, arritmias cardíacas, hematotoxicidade e danos neurológicos, além de danos psicossociais ocasionados por prejuízos financeiros às populações de áreas atingidas 5 .

Editora Unijuí - Revista Contexto \& Saúde - ISSN 2176-7114 - v. 21, n. 44, out./dez. 2021 
Embora a exploração do petróleo tenha retorno positivo em termos de economia e tecnologia, já foram registrados muitos desastres ambientais em decorrência dessa exploração. Dada a extensão de derramamentos de petróleo em ambiente marinho e suas consequências, o objetivo deste estudo foi revisar os efeitos da contaminação marinha por óleo, em cenário nacional e internacional, e descrever as principais implicações toxicológicas e/ou patológicas ao meio ambiente e à saúde humana.

\section{MÉTODOS}

O presente estudo é uma revisão da literatura do tipo narrativa. As buscas foram realizadas nas bases de dados Periódicos Capes, Scielo, Google Scholar e Pubmed. Os descritores utilizados foram: "derramamento de petróleo", "vazamento de óleo no mar", "oil spill", "sea" e "petroleum", Foram selecionados 28 artigos, nacionais e internacionais, publicados entre 2004 e 2020, para abranger estudos sobre acidentes ocorridos no período e, assim, compor esta revisão. Outras referências complementares foram utilizadas para discussão dos dados.

\section{RESULTADOS E DISCUSSÃO}

\section{Alguns desastres ambientais por derramamento de petróleo no oceano}

Dentre os principais vazamentos de petróleo ocorridos no oceano mundialmente, destaca-se, como um dos mais antigos documentados, o naufrágio do navio Torrey Canyon, no litoral da Inglaterra em 1967, que afetou tanto a costa inglesa quanto a francesa, com 120 toneladas de óleo derramadas, e, ainda, o derramamento do petroleiro Exxon Valdez, em 1989, que contaminou uma área de $800 \mathrm{Km}^{10}$. Na costa francesa ocorreu, ainda, o acidente com o navio petroleiro Erika, em dezembro de 1999 na Bretanha, que naufragou devido a uma rachadura em seu casco. Este último ocorreu, possivelmente, em consequência de avaliações inadequadas das condições de navegação, derramando no ambiente marinho 20 mil toneladas de óleo ${ }^{11}$. Na Nigéria tem ocorrido o constante derramamento de petróleo bruto e subprodutos em diversos oleodutos espalhados por diferentes regiões do país, causando inúmeros danos ambientais e sociais, contaminando a água e o solo no Delta do Níger ${ }^{12}$.

Outro grande acidente, considerado um dos mais impactantes envolvendo derramamento de petróleo, foi o ocorrido em 20 de abril de 2010 no Golfo do México, Estados Unidos. Na ocasião, houve a explosão da plataforma Deepwater Horizon, operada pela multinacional British Petroleum, poluindo uma grande área do oceano com mais de $500.000 \mathrm{~m}^{3}$ de óleo ${ }^{13}$. O óleo derramado afetou centenas de quilômetros de distância do poço onde aconteceu a explosão, atingindo elevadas proporções e sendo de difícil controle. A recuperação da saúde do ecossistema estendeu-se por mais de sete anos após essa tragédia ambiental, e ainda está sob avaliação ${ }^{14}$. Os efeitos persistentes dessa contaminação são graves e podem ser extrapolados para outras situações, como as vivenciadas em solo brasileiro. Ribeiro ${ }^{5}$ afirma que é relevante lembrar desse acidente, tendo em

Editora Unijuí - Revista Contexto \& Saúde - ISSN 2176-7114 - v. 21, n. 44, out./dez. 2021 
vista que a exploração feita no local é parecida com a que é realizada no Pré-sal, área localizada a $7.000 \mathrm{~m}$ de profundidade no interior da plataforma continental brasileira em atividade.

No Brasil, dentre os principais desastres ambientais envolvendo exploração de petróleo, destacam-se o vazamento de 700 mil litros de gasolina que causou um incêndio e 93 mortes nas palafitas da comunidade de Vila Socó, em Cubatão (SP), devido a falhas nos gasodutos subterrâneos da Petrobras, tendo repercussão internacional ${ }^{9}$. No Rio de Janeiro houve dois vazamentos: na Baía de Guanabara (RJ) em 2000, quando um navio petroleiro derramou mais de um milhão de litros de óleo cru, e na Bacia de Campos, no ano de 2011, quando mais de 3 mil barris de petróleo foram derramados no mar pela empresa Chevron ${ }^{15}$. A Bacia de Campos é a maior produtora de petróleo offshore (no mar) do país e já foi cenário de outros acidentes, como o da plataforma P-36, em 2001, considerado um dos graves acidentes internacionais ligados à indústria petrolífera, o que pode indicar um atraso na gestão tecnológica e de riscos dessas atividades ${ }^{16}$.

Em setembro de 2019 ocorreu um derramamento de óleo na costa litorânea do Nordeste brasileiro que, em nota à imprensa, a Marinha do Brasil (MB) declarou ser petróleo cru, afetando extensas áreas de diversos Estados litorâneos ${ }^{17}$. Após 9 meses do desastre, as manchas de óleo ressurgiram no litoral nordestino e também no litoral do Espírito Santo, oriundas do mesmo óleo que havia assentado e acumulado no leito do oceano e se desprendeu em decorrência de condições meteorológicas, como ventos e correntes marítimas ${ }^{18}$.

Infere-se que, devido à presença de compostos tóxicos presentes no petróleo, o impacto desses derramamentos ocorra sobre as plantas, animais e seres humanos, de forma aguda e crônica, além de influenciar a economia local das regiões afetadas, com a diminuição da comercialização dos pescados e desvalorização do turismo.

\section{Aspectos gerais da toxicidade dos componentes do petróleo}

Ao ser lançado no mar, quanto maior é o tempo de exposição do petróleo a fenômenos do intemperismo maior é o dano causado ao ambiente e mais difícil de ser recuperado ${ }^{19}$. Os HPAs recebem a classificação de poluentes orgânicos persistentes (POPs) por serem tóxicos, persistentes, bioacumuláveis, transportados por longas distâncias por meio do ar, podendo contaminar alimentos e serem acumulados ao longo da cadeia alimentar, fenômeno chamado de biomagnificação que, por fim, causam efeitos negativos sobre a saúde e o ambiente. $O$ acúmulo do HPAs pode ocorrer no fígado (em peixes), no hepatopâncreas ou na glândula digestiva (em crustáceos, anelídeos e moluscos) e em diversos órgãos (nos mamíferos, iniciando pelo fígado). A absorção dos HPAs está intimamente relacionada à sua propriedade lipofílica, e esta característica pode resultar em uma mudança da estrutura da membrana e interferência no funcionamento da célula, revelando o caráter mutagênico desse composto. Para exercer esse efeito, a substância precisa ser ativada pela metabolização, pois, ao passar pelo mecanismo de biotransformação, esses compostos tornam-se eletrofílicos e mais reativos, aumentando a possibilidade de se associarem e causarem danos a substratos endógenos, como proteínas, membranas e o material genético (DNA ${ }^{20}$.

Editora Unijuí - Revista Contexto \& Saúde - ISSN 2176-7114 - v. 21, n. 44, out./dez. 2021 


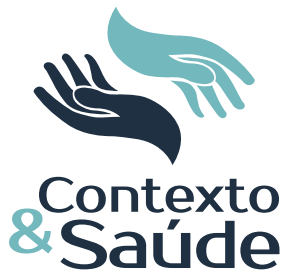

O benzeno, um dos principais HPAs presente na composição química do petróleo, é uma substância volátil e, por isso, a realização de testes in vitro é limitada. Apesar disso, Luijten et al. ${ }^{21}$ retrataram que o benzeno e seus metabólitos induziram alterações cromossômicas em testes feitos in vitro em células de mamíferos, e em testes in vivo, realizados em animais expostos ao benzeno por inalação, esse composto apresentou baixo potencial tóxico em induzir alterações genéticas. Teve, no entanto, um maior poder de alteração hematológica, com redução de eritrócitos, leucócitos e plaquetas, sendo relevante considerar que os animais tiveram menor tempo de exposição que trabalhadores de indústrias petroquímicas tendem a ter, além de possuírem aparelho respiratório mais simples.

A exposição ao benzeno em casos de acidente, por exemplo, é aguda e com uma relação dose $x$ tempo pouco avaliada, pois, em casos de derramamento de óleo no oceano, compostos, como o benzeno, sofrem volatilização em decorrência do processo de intemperização que ocorre no petróleo. Isso, geralmente, ocorre 24 horas depois do desastre. Desse modo, quando o óleo chega à costa, sua constituição já está modificada22.

Mesmo assim, os danos oriundos da exposição a estes voláteis e aos componentes persistentes do petróleo são amplos e atingem o ecossistema e a saúde humana, ou por exposição direta ou indireta, associando-se à complexidade da cadeia alimentar e aos fatores sociais e ocupacionais.

\section{Efeitos tóxicos dos componentes do petróleo no ecossistema}

A cadeia produtiva do petróleo, mesmo com toda regulamentação pela Agência Nacional do Petróleo (ANP), possui impactos ambientais intrínsecos. Dentre esses, os principais são a variação da qualidade das águas, do ar e do solo. A mudança na qualidade da água se dá pelo lançamento dos rejeitos na água do mar, o que influencia na turbidez e diminuição da concentração de oxigênio dissolvido na água, influenciando a capacidade fotossintética dos organismos fitoplanctônicos e a alimentação dos organismos filtradores, pois esses podem ter seus sistemas bloqueados por material sólido em suspensão. A variação da qualidade do ar é impactada pelas emissões de gases, como óxidos de nitrogênio (NOx), monóxido de carbono (CO), dióxido de enxofre $\left(\mathrm{SO}_{2}\right)$, dióxido de carbono $\left(\mathrm{CO}_{2}\right)$, metano $\left(\mathrm{CH}_{4}\right)$, óxido nítrico (NO) e material particulado, resultante do funcionamento de exaustores de máquinas e turbinas, além da queima de hidrocarbonetos. $\mathrm{O} \mathrm{CO}_{2}$ e $\mathrm{CH}_{4}$ são relacionados ao aumento do efeito estufa e, portanto, possuem diversas implicações em questões ambientais. Por fim, a alteração da qualidade do solo ocorre pela remoção da vegetação para instalação do poço, o que diminui a defesa natural do solo, tornando-o mais susceptível à erosão e à contaminação pela utilização do cascalho com óleo ao redor do poço23.

Os HPAs presentes na composição do petróleo são intensamente poluentes e de difícil degradação, causando efeitos danosos ao meio ambiente. Essas substâncias, como benzeno e tolueno, ficam acumuladas no solo e contaminam a fauna e a flora. Quanto à fauna marinha, pode ocorrer, dentre outros efeitos, danos ao DNA, redução do crescimento e surgimento de malformações e, também, mudança da estrutura etária das populações devido à perda de peixes mais jovens. Em ecossistemas terrestres, o óleo pode se acumular nas penas e até

Editora Unijuí - Revista Contexto \& Saúde - ISSN 2176-7114 - v. 21, n. 44, out./dez. 2021 


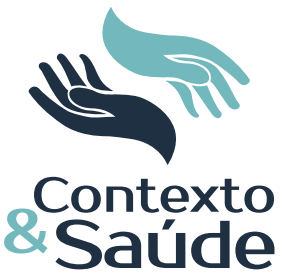

mesmo no fígado de aves. Além disso, ocorre prejuízo na ação fotossintética de plantas em manguezais ${ }^{24}$. No acidente da plataforma no Golfo do México as consequências para a diversidade marinha, em âmbito da zona pelágica, foi a mortandade de larvas de peixes, o que pode ter causado a perda de uma geração desses peixes. Além disso, octocorais coloniais morreram, pois eram ancorados em região profunda do oceano e foram cobertos com material do óleo ${ }^{25}$.

No desastre ambiental ocorrido no litoral do nordeste brasileiro, o efeito das manchas de óleo sobre as comunidades bentônicas recifais foi avaliado em quatro praias do litoral norte baiano. Os resultados indicaram redução na variedade de espécies bentônicas e no número de animais vivos após a ocorrência do desastre ${ }^{26}$.

Além dos derramamentos de petróleo, efluentes industriais, esgotos, atividades de mineração e fertilizantes são potenciais fontes para a entrada de metais tóxicos e hidrocarbonetos de petróleo na zona costeira, como é o caso dos manguezais. Esse ecossistema marinho tende a acumular os poluentes orgânicos e metais em seu sedimento. A fauna intrínseca do manguezal ou a que utiliza esse ecossistema pode morrer por sufocamento ou por absorção de frações tóxicas solúveis, pode ter perda de mobilidade, sofrer distúrbios na respiração e reprodução, entre outros ${ }^{27}$.

A bioacumulação dos compostos do petróleo em alimentos marinhos (pescados e algas) é um processo previsível, no entanto ainda há muitas limitações relacionadas a estudos longitudinais que podem esclarecer um período seguro de reparação dos danos químicos neste ambiente, que impactam na cadeia alimentar e, consequentemente, na saúde humana.

\section{Efeitos tóxicos do petróleo e seus derivados na saúde humana}

A maioria dos estudos que tratam dos impactos dos acidentes por derramamento de óleo na saúde humana são, em geral, estudos transversais, ou seja, feitos em um período específico de tempo, sem analisar, portanto, indicadores anteriores ou a longo prazo para fins de comparação individual dentro dos grupos expostos. Além disso, os efeitos do petróleo em espécies marinhas são mais amplamente realizados em detrimento das implicações para a espécie humana. Apesar disso, existem evidências de efeitos tóxicos agudos decorrentes da exposição ao óleo, como irritações cutâneas e de mucosas, efeitos genotóxicos e endócrinos, além de efeitos psicológicos ${ }^{28}$.

\section{Efeitos tóxicos diretos do petróleo e seus derivados}

Em relação a estudos de avaliação da exposição ocupacional ao benzeno, Jingchao et al..$^{29}$ avaliaram 58 trabalhadores expostos a esse composto por, no mínimo, um ano em uma oficina de pintura na China e 83 trabalhadores de uma fábrica de calçados, e acompanharam outros 35 trabalhadores no período de 2009 a 2013, avaliando a hematotoxicidade dessa exposição. Foi demonstrado que houve hipermetilação de sequências de genes de reparo do DNA nos trabaIhadores expostos em relação ao grupo controle. Quanto ao grupo acompanhado em coorte, essa hipermetilação diminuiu na medida em que também reduziu a exposição ao benzeno. De Brito Oliveira Costa e Pacheco ${ }^{30}$ referem diversas

Editora Unijuí - Revista Contexto \& Saúde - ISSN 2176-7114 - v. 21, n. 44, out./dez. 2021 


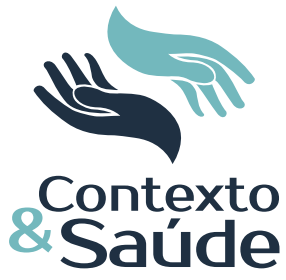

consequências da hipermetilação de genes, como a relação com o câncer e o silenciamento de genes importantes nos processos do ciclo celular. Outro estudo realizado na Tailândia, que incluiu 150 trabalhadores de postos de gasolina, com jornada de trabalho de 8 horas diárias, concluiu, por meio de medidas quantitativas das concentrações e exposições, que a exposição crônica pode aumentar o risco de câncer ${ }^{31}$.

Holder et al. ${ }^{32}$ demonstraram maiores riscos associados à exposição aguda aos compostos orgânicos voláteis presentes no petróleo. Nesse estudo foi analisado o risco da exposição por inalação de compostos como benzeno e tolueno na exploração de poços de Petróleo e Gás no Colorado, Estados Unidos. Foram avaliadas diferentes exposições que combinavam distância e tempo de exposição a diferentes substâncias componentes do petróleo na distância de 500 a 2.000 pés. A exposição aguda considerou o tempo de uma hora, a subcrônica a exposição de até um ano e a crônica considerou exposições de 30 a 32 anos ao benzeno. Na exposição aguda o efeito tóxico hematológico foi o mais crítico e associado, principalmente, ao benzeno. Os efeitos subcrônicos indicaram, além de hematotoxicidade, a neurotoxicidade.

Considerando os efeitos da inalação do benzeno, bem como sua considerável rápida volatilização no oceano, os danos tóxicos oriundos deste componente parecem repercutir, em especial, nas comunidades que residem próximas aos locais dos desastres de derramamento do óleo e em trabalhadores diretamente envolvidos com atividades de limpeza das áreas.

Bruederle e Hodler ${ }^{12}$ estudaram os efeitos do derramamento de óleo nas taxas de mortalidade neonatal e infantil na Nigéria, nas proximidades do Delta do Níger. Mediante um monitor de derramamento, foram identificados registros de acidentes entre 2005 e 2014, além de informações sobre a sobrevivência de crianças concebidas antes e depois desse período, há uma distância de até 10 quilômetros dos locais de derramamento. Os tipos de exposição a que as mães estiveram expostas incluíam partículas respiráveis, contato dérmico e ingestão de água, peixes e alimentos cultivados na região. Foi verificado que a mortalidade neonatal aumentou em 38,3 mortes por 1.000 nascidos vivos, concluindo que o contato com hidrocarbonetos oferece potencial risco teratogênico.

\section{Evidências dos riscos da ingestão de pescados e mariscos contaminados com o petróleo}

No que diz respeito à exposição aos HPAs, via ingestão, Lemiere et al. ${ }^{11}$ estimaram o potencial genotóxico do consumo de alimentos marinhos contaminados por HPAs em mamíferos. Para isso, mexilhões retirados do mar da Costa Sul da Bretanha, França, após o naufrágio do navio-tanque Erika, foram oferecidos a ratos diariamente por um período de 15 a 30 dias. Os mexilhões foram analisados quanto ao seu grau de contaminação, distribuídos em três lotes, e utilizados aqueles que continham níveis próximos aos estabelecidos pela Agence Française de Securité Sanitaire dês Aliments (AFSSA), a fim de testar a relevância da recomendação. Foram observados efeitos genotóxicos no fígado e na medula óssea dos animais, sendo os danos de intensidade proporcional ao grau de contaminação dos mexilhões.

Editora Unijuí - Revista Contexto \& Saúde - ISSN 2176-7114 - v. 21, n. 44, out./dez. 2021 
Resende et al..$^{33}$ avaliaram níveis de hidrocarbonetos policíclicos alifáticos e aromáticos na água do mar e de HPAs em peixes na Baía de Guanabara (RJ). Quanto aos resultados, foi observado que as concentrações de HPAs na água se mantiveram abaixo do limite estabelecido na Resolução Conama no 357/2005³4, referente às diretrizes ambientais. Em relação aos peixes, os níveis de hidrocarbonetos mostraram-se proporcionais às áreas de baixo impacto antropogênico. Os autores ressaltam, no entanto, a importância da realização de novas amostragens para obtenção de dados que possibilitem melhor caracterização da área em estudo.

Após o desastre ambiental no litoral do nordeste brasileiro, foi observada a presença de óleo no trato digestivo de animais recolhidos em praias do Estado da Bahia. Este óleo pode ter sido ingerido acidentalmente pelos animais marinhos quando há dissolução de pelotas de óleo na água do mar, especialmente em horários de maior incidência solar ${ }^{26}$. Deve ser incentivada a realização de estudos que possam elucidar a presença de contaminantes químicos nos organismos marinhos, além da água, com o objetivo de identificar o grau de contaminação desses alimentos, com vistas à segurança alimentar da população consumidora de pescado.

\section{Aspectos psicossociais e psicológicos associados ao derramamento de petróleo no oceano}

Além dos riscos químicos nos aspectos estritamente fisiológicos, o derramamento de petróleo nos oceanos pode também afetar a saúde humana em aspectos psicológicos. A limpeza das áreas afetadas é considerada um fator estressor. Isso porque, em geral, é realizada manualmente pela população local das áreas afetadas, especialmente por indivíduos que utilizam o mar como fonte de sustento ou complemento de renda e alimentação ${ }^{24}$.

Kwok et al. ${ }^{35}$ documentaram o impacto psicológico de indivíduos que participaram da limpeza do óleo derramado no acidente no Golfo do México. O estudo demonstrou que os impactos causados pelo derramamento, como danos ao ecossistema, interrupção das indústrias locais, incluindo a pesca, e a incerteza sobre os efeitos do petróleo na saúde da população, causaram um aumento do risco de eventos psicológicos adversos. Quanto aos indivíduos que participaram diretamente dos trabalhos de limpeza, foram investigadas as exposições à inalação do óleo, ao contato dérmico, ao calor durante a limpeza e se eram pescadores antes do desastre. Os autores sugeriram que houve maior prevalência de depressão e transtorno de estresse pós-traumático relacionados com o trabalho nesse grupo de indivíduos.

No acidente ocorrido na costa do Nordeste brasileiro, muitos voluntários atuaram na limpeza das praias afetadas, incluindo pescadores, moradores locais, estudantes, turistas e esportistas. Essa população foi exposta ao óleo cru sem a utilização de equipamentos de proteção individual adequados e sem métodos profissionais de limpeza. Os impactos psicológicos desses indivíduos envolvidos diretamente na limpeza ainda não são conhecidos, no entanto, referente aos pescadores locais e ao setor turístico, um estudo realizado no Estado de Pernam-

Editora Unijuí - Revista Contexto \& Saúde - ISSN 2176-7114 - v. 21, n. 44, out./dez. 2021 
buco concluiu que houve um considerável impacto negativo na venda de pescados, além de um aumento do desemprego de trabalhadores do ramo turístico ${ }^{36}$.

Um estudo feito no Delta do Níger discute que países em desenvolvimento, como Angola e Nigéria, sofrem impactos piores em um cenário de acidente envolvendo a exploração de petróleo, uma vez que existe falta de gestão, estratégias e respostas políticas eficientes. No caso das comunidades nigerianas estudadas, evidenciou-se que não somente o meio ambiente, mas também a cultura, as tradições e a economia local, sofreram impactos graves ${ }^{37}$.

De forma geral, os danos causados por desastres ambientais, como o derramamento de petróleo cru no litoral nordestino, impactam, prioritariamente, pessoas que usufruem do ambiente afetado ou que dependem dele economicamente, pois os mesmos têm redução ou impedimento de vendas, base alimentar modificada, além de conviver com as incertezas derivadas do ocorrido. Uma vez que desastres desse porte exercem notável impacto negativo na sociedade, são necessários estudos bem delineados com a finalidade de traçar um panorama das condições de saúde mental das populações atingidas e viabilizar estratégias de enfrentamento desses problemas, por inclusão das mesmas em políticas públicas assistenciais, além das estratégias de remediação e minimização dos danos químicos.

\section{Alternativas para minimizar os danos ambientais oriundos do derramamento de petróleo}

Rainha et al. ${ }^{19}$ investigaram o efeito do intemperismo como principal processo de remediação natural do ecossistema. O fenômeno estudado foi a evaporação, por ser um dos principais processos intempéricos que ocorrem sobre petróleo derramado, além de ser altamente importante em países com clima tropical. Foram utilizadas duas amostras de petróleo bruto de campos de produção diferentes por processo de destilação, simulando a exposição do petróleo no mar. Esse fenômeno causa a diminuição da massa de petróleo, o que pode ser positivo, uma vez que reduz a mancha de óleo, no entanto as moléculas mais pesadas que restam podem ser de difícil remoção. Dessa forma, os autores destacam que o retardo em ações de retirada de petróleo aumenta a dificuldade de remoção desse produto do meio aquático.

Para minimizar os danos e fazer com que o óleo derramado tivesse alguma utilidade, foi realizado um experimento piloto no Projeto Compostagem Francisco da Universidade Federal da Bahia (Ufba). O projeto utiliza bioaceleradores para fazer a degradação de resquícios de alimentos crus e cozidos. Como os bioaceleradores mostraram-se eficientes também para degradar a matéria orgânica do coco, produzindo fertilizante orgânico, os pesquisadores testaram com o petróleo que, em 60 minutos, se transformou em carvão. Os pesquisadores, entretanto, ressaltam que são necessários estudos para verificar se o uso desse carvão é seguro, bem como sua possível utilidade, posto que é diferente do carvão tradicional ${ }^{38}$.

No estudo realizado por Paiva ${ }^{39}$, a compostagem também foi utilizada como possibilidade para minimizar a toxicidade de derivados do petróleo; nesse caso sendo aplicada ao óleo diesel e ao óleo lubrificante do solo. O método em-

Editora Unijuí - Revista Contexto \& Saúde - ISSN 2176-7114 - v. 21, n. 44, out./dez. 2021 
pregado contou com raquetes de palma forrageira ficus, casca de ovo triturada, serrapilheira, esterco caprino e borra de café. Com a realização do experimento, observou-se, entre os resultados, a adsorção dos óleos e a formação de biossurfactantes. Após análise da redução da toxicidade, os pesquisadores identificaram utilidade do produto como adubo orgânico.

Da Silva ${ }^{40}$ elaborou um trabalho no qual analisou o uso de micro-organismos na biorremediação de solo com contaminação por compostos provenientes do petróleo. Para isso, utilizou a combinação de bactérias e fungos com soluções de nutrientes. Foram analisados parâmetros como umidade, mudanças de $\mathrm{pH}$, alterações no teor de carbono e remoção dos compostos oriundos do petróleo, sendo eles benzeno, tolueno e xilenos, considerando-se que os resultados demonstraram redução desses compostos nos campos estudados.

Diante desse contexto, entende-se que existem métodos alternativos com resultados promissores no que se refere à biotransformação e redução do potencial tóxico dos componentes do petróleo; no entanto, ainda não apresentam etapas de pesquisas avançadas. São necessários mais estudos com o objetivo de fundamentar melhor tais procedimentos, sobretudo com o petróleo em seu estado bruto, como ocorreu em muitos acidentes de derramamento, inclusive no Nordeste brasileiro.

\section{CONSIDERAÇÕES FINAIS}

O derramamento de petróleo no mar é um desastre ambiental de extensa gravidade. Já são comprovados os efeitos prejudiciais que seus compostos causam, podendo acarretar consequências nocivas tanto para o meio ambiente quanto para a saúde humana. Os efeitos são previsíveis, mas estudos longitudinais são necessários para a identificação da magnitude da bioacumulação e persistência dos danos químicos. A literatura científica carece de dados que possam estabelecer prazos ou períodos de recuperação do ambiente e que possam, igualmente, trazer segurança à população quanto à utilização dos insumos marinhos bem como o contato direto com o ambiente contaminado.

Apesar da ocorrência de vários desastres em âmbito mundial, ainda existem limitações quanto às estratégias de tomadas de decisão das empresas e setores governamentais envolvidos, quanto à remediação imediata no sentido de acelerar o intemperismo do petróleo, e quanto à proteção adequada da população mais vulneravelmente exposta aos compostos químicos e aos danos psicossociais.

\section{REFERÊNCIAS}

${ }^{1}$ Martins SS da S, Azevedo MO de, Silva MP da, Silva VP da. Produção de petróleo e impactos ambientais: algumas considerações. Holos [Internet]. 2015 [citado 10 ago. 2019];6(31). Disponível em: https://www2.ifrn.edu.br/ojs/index.php/HOLOS/article/ view/2201

2 Da Cruz GF, Marsaioli AJ. Natural processes of petroleum biodegradation in reservoirs [Internet]. Química Nova. Sociedade Brasileira de Química. 2012 [citado 11 ago. 
2019];25:1628-34. Disponível em: http://www.scielo.br/j/qn/a/mmRRqpwG89kVhnQNpwgrrNn/?lang=pt

3 Lucchesi CF. Petróleo. Estud Avançados [Internet]. 1998 ago [citado 21 nov. 2019];12(33):17-40. Disponível em: http://www.scielo.br/j/ea/a/RDLx4Hjt5zTdhhQSSj8w3xk/abstract/?lang=pt

${ }^{4}$ Nascimento CAO, Moro LFL. Petróleo: energia do presente, matéria-prima do futuro? Rev USP [Internet]. 2011;0(89):90-7. Disponível em: https://www.revistas.usp.br/revusp/article/view/13871

${ }^{5}$ Ribeiro H. Impactos de exploração do petróleo na saúde humana. Rev USP [Internet]. 2012;0(95):61-71. Disponível em: https://www.revistas.usp.br/revusp/article/ view/52239

${ }^{6}$ Agência Nacional do Petróleo GN e B. Petróleo e Derivados [Internet]. ANP. 2016 [citado 12 nov. 2019. Disponível em: http://www.anp.gov.br/component/content/article/2-uncategorised/709-petroleo-e-derivados

7 Inca. Hidrocarbonetos Policíclicos Aromáticos - HPA [Internet]. Instituto Nacional do Câncer. 2018 [citado 12 ago. 2020]. Disponível em: https://www.inca.gov.br/exposicao-no-trabalho-e-no-ambiente/poluentes/hidrocarbonetos-policiclicos-aromaticos-hpa

${ }^{8}$ Ifegwu OC, Anyakora C. Polycyclic Aromatic Hydrocarbons: Part I. Exposure. In: Advances in Clinical Chemistry. Elsevier; 2015. p. 277-304.

${ }^{9}$ Klanovicz J, Ferreira Filho CB. A fabricação de uma cidade tóxica: A Tribuna de Santos e os desastres tecnológicos de Cubatão (Brasil) na década de 1980. Rev Cad. do Ceom. 2018 jun 4;31(48):10.

${ }^{10}$ de Noronha IR, Ferreira MIP, Pinto AEM. Riscos e danos ambientais associados às atividades da cadeia produtiva do petróleo: instrumentos de comando e controle para mitigação dos impactos de vazamentos de óleo. Rev Gestão Sustentabilidade Ambient [Internet]. 2018;7(1):596-613. Disponível em: http://www.portaldeperiodicos.unisul. br/index.php/gestao_ambiental/article/view/6013

${ }^{11}$ Lemiere S, Cossu-Leguille C, Bispo A, Jourdain MJ, Lanhers MC, Burnel D et al. DNA damage measured by the single-cell gel electrophoresis (Comet) assay in mammals fed with mussels contaminated by the "Erika" oil-spill. Mutat Res - Genet Toxicol Environ Mutagen. 2005 mar. 7;581(1-2):11-21.

${ }^{12}$ Bruederle A, Hodler R. Effect of oil spills on infant mortality in Nigeria. Proc Natl Acad Sci U S A [Internet]. 2019 mar. 19 [cited 2019 Nov 20];116(12):5467-71. Disponível em: https://www.pnas.org/content/116/12/5467

${ }^{13}$ Beyer J, Trannum HC, Bakke T, Hodson P V., Collier TK. Environmental effects of the Deepwater Horizon oil spill: A review. Mar Pollut Bull. 2016 set. 15;110(1):28-51.

${ }^{14}$ McClain CR, Nunnally C, Benfield MC. Persistent and substantial impacts of the Deepwater Horizon oil spill on deep-sea megafauna. R Soc Open Sci [Internet]. 2019;6(8). Disponível em: https://royalsocietypublishing.org/doi/abs/10.1098/rsos.191164

${ }^{15}$ Gonçalves DP. Principais desastres ambientais no Brasil e no mundo [Internet]. Jornal da Unicamp. 2017 [citado 10 ago. 2019]. Disponível em: https://www.unicamp.br/unicamp/ju/noticias/2017/12/01/principais-desastres-ambientais-no-brasil-e-no-mundo

${ }^{16}$ Figueiredo MG, Alvarez D, Adams RN. O acidente da plataforma de petróleo P-36 revisitado 15 anos depois: da gestão de situações incidentais e acidentais aos fatores organizacionais. Cad Saúde Pública [Internet]. 2018 mar. 29 [citado 25 nov. 2019];34(4):34617. Disponível em: http://www.scielo.br/j/csp/a/Z43R7kQWZ3Mpwvkr5LKzmJm/abstract/?lang=pt

${ }^{17}$ Brasil M do. Nota à imprensa em 27 de setembro de 2019 [Internet]. Brasília, DF. 2019 [citado 12 nov. 2019]. Disponível em: https://www.marinha.mil.br/sites/default/files/ nota_a_imprensa_-_manchas_negras_nas_praias_do_nordeste_27set.pdf

${ }^{18}$ Marinha do Brasil. Nota à imprensa em 29 de junho de 2020 [Internet]. Brasília, DF. 2020 [citado 12 nov. 2020]. Disponível em: https://www.marinha.mil.br/sites/default/ files/nota_a_imprensa_ressurgimento_de_vestigios_de_oleo.pdf

${ }^{19}$ Rainha KP, Amorim JL, Senna JN, Ferreira SAD, Oliveira LMSL, Guimarães RCL et al. $57^{\circ}$ $\mathrm{CBQ}$ - Estudo de intemperismo de petróleo para minimizar impactos ambientais [In- 
ternet]. $57^{\circ}$ Congresso Brasileiro de Química. 2017. Disponível em: http://www.abq. org.br/cbq/2017/trabalhos/5/11739-24886.html

${ }^{20}$ Garcia LPA, Gonçalves BL, Panho G, Scussel VM. Hidrocarbonetos policíclicos aromáticos em alimentos: uma revisão. Pubvet [Internet]. 2014 [citado 6 ago. 2019];8(19):2292450. Disponível em: http://www.pubvet.com.br/artigo/1470/hidrocarbonetos-policiacuteclicos-aromaacuteticos-em-alimentos-uma-revisatildeo

${ }^{21}$ Luijten M, Ball NS, Dearfield KL, Gollapudi BB, Johnson GE, Madia F et al. Utility of a next generation framework for assessment of genomic damage: A case study using the industrial chemical benzene [Internet]. Vol. 61, Environmental and Molecular Mutagenesis. Wiley-Blackwell; 2020 [citado 30 nov. 2020]. p. 94-113. Disponível em: /pmc/ articles/PMC6972600/

${ }^{22}$ (COES-BA) CO de emergência em saúde (Bahia). Protocolo de avaliação da saúde de população exposta a petróleo: orientações aos Serviços de Profissionais de Saúde da Bahia. [Internet]. Bahia. 2020 [citado 13 ago. 2020]. Disponível em: http://renastonline.ensp.fiocruz.br/sites/default/files/arquivos/recursos/protocolo_avasaude_expostos_petroleo_ba_15jan2020.pdf

${ }^{23}$ Martins SS da S, Azevedo MO de, Silva MP da, Silva VP da. Produção de petróleo e impactos ambientais: algumas considerações. Holos [Internet]. 11 dez. 2015 [citado 7 out. 2021];6(0):54-76. Disponível em: https://www2.ifrn.edu.br/ojs/index.php/HOLOS/article/view/2201

${ }^{24}$ Euzebio CS, Rangel G da S, Marques RC. Derramamento de petróleo e seus impactos no ambiente e na saúde humana. Rev Bras Ciências Ambient [Internet]. 2019 nov. 2 [citado 30 nov. 2019];52(52):79-98. Disponível em: http://www.rbciamb.com.br/index. php/Publicacoes_RBCIAMB/article/view/588

${ }^{25}$ Fisher CR, Montagna PA, Sutton TT. How did the Deepwater Horizon oil spill impact deep-sea ecosystems? Oceanography. 2016 Sep. 1;29(3):182-95.

${ }^{26}$ Kelmo F. Efeito das manchas de óleosobre as comunidadesbentônicasrecifais. In: Mesa Redonda: 0 que podemos tirar após 08 meses de derramamento de óleo no litoral nordestino? In Congresso virtual UFBA 2020; 2020. Disponível em: https://www.youtube.com/watch?v=aAahu-Sdp4c

${ }^{27}$ Alencar T, Oliveira VDP, Oliveira M, Saraiva V. Contaminação por metais pesados e hidrocarbonetos de petróleo: uma ameaça para os manguezais. Bol do Obs Ambient Alberto Ribeiro Lamego. 2016 dez. 30;10:7.

${ }^{28}$ Aguilera F, Méndez J, Pásaroa E, Laffona B. Review on the effects of exposure to spilled oils on human health [Internet]. Journal of Applied Toxicology. J Appl Toxicol; 2010 [citado 7 out. 2021];30:291-301. Disponível em: https://pubmed.ncbi.nlm.nih. gov/20499335/

${ }^{29}$ Jingchao R, Jun-peng C, Mengkai L, Huan L, Pengfei H, Xiao W. The prevalence and persistence of aberrant promoter DNA methylation in benzene-exposed Chinese workers. PLoS One [Internet]. 2019;14(8):1-14. Disponivel em: https://doi.org/10.1371/journal. pone. 0220500

${ }^{30}$ De Brito Oliveira Costa E, Pacheco C. Epigenética: regulação da expressão gênica em nível transcricional e suas implicações. Semin Ciências Biológicas e da Saúde. 24 dez. 2013;34(2):125.

${ }^{31}$ Chaiklieng S, Suggaravetsiri P, Autrup H. Risk assessment on benzene exposure among gasoline station workers. Int J Environ Res Public Health [Internet]. 2019 jul. 2 [citado 12 nov. 2019];16(14). Disponível em: /pmc/articles/PMC6678808/

${ }^{32}$ Holder C, Hader J, Avanasi R, Hong T, Carr E, Mendez B et al. Evaluating potential human health risks from modeled inhalation exposures to volatile organic compounds emitted from oil and gas operations. J Air Waste Manag Assoc. 2 dez. 2019;69(12):1503-24.

${ }^{33}$ Resende L, Pedrete T, Nudi A, Wagener A. Nível de contaminação por hidrocarbonetos na Baía de Guanabara, Rio de Janeiro, RJ. Revista Brasileira de Iniciação científica. 2017;4 [Internet]. Disponível em: https://periodicos.itp.ifsp.edu.br/index.php/IC/article/view/330 
${ }^{34}$ Conselho Nacional do Meio Ambiente - Conama. Resolução Conama N 357, de 17 de março de 2005. Dispõe sobre a classificação dos corpos de água e diretrizes ambientais para o seu enquadramento, bem como estabelece as condições e padrões de lançamento de efluentes, e dá outras providências. Brasília; 2015.

${ }^{35}$ Kwok RK, McGrath JA, Lowe SR, Engel LS, Jackson WB, Curry MD et al. Mental health indicators associated with oil spill response and clean-up: cross-sectional analysis of the GuLF STUDY cohort. Lancet Public Heal [Internet]. 2017 Dec 1 [citado 2 nov. 2019];2(12):e560-7. Disponível em: https://pubmed.ncbi.nlm.nih.gov/29253441/

${ }^{36}$ Araújo ME de, Ramalho CWN, Melo PW de. Artisanal fishers, consumers and the environment: immediate consequences of the oil spill in Pernambuco, Northeast Brazil. Cad Saude Publica [Internet]. 2020 jan 20 [citado 10 ago. 2020];36(1):e00230319. Disponível em: http://www.scielo.br/j/csp/a/66t7BVfM6X4pBBCJwLcqmjf/?lang=pt

${ }^{37}$ Albert ON, Amaratunga D, Haigh RP. Evaluation of the Impacts of Oil Spill Disaster on Communities and Its Influence on Restiveness in Niger Delta, Nigeria. Procedia Eng. 2018 jan. 1;212:1054-61.

${ }^{38}$ Leite D. Projeto transforma petróleo encontrado no mar do Nordeste em carvão. [Internet]. Juiz de Fora, MG. 2019 [citado 12 nov. 2019]. Disponível em: https://noticias.uol. com.br/meio-ambiente/ultimas-noticias/redacao/2019/10/21/projeto-transforma-petroleo-encontrado-no-mar-do-nordeste-em-carvao.htm

${ }^{39}$ Paiva I de AM. Potencial do uso da compostagem como meio de diminuição da toxicidade de derivados do petróleo. Bibl Digit Teses e Diss da UFCG [Internet]. 2017. Disponível em: http://dspace.sti.ufcg.edu.br:8080/jspui/handle/riufcg/4964

40 da Silva WM. Utilização de microrganismos na biorremediação de solo contaminado por derivados de petróleo [Internet]. Repositório Institucional Unesp. Universidade Estadual Paulista (Unesp); 2018. Disponível em: https://repositorio.unesp.br/handle/11449/154212 